\author{
Paper presented at the \\ Swedish Institute of International Affalrs \\ Seminar on AFGHANISTAN - A THREATENED CULTURE \\ Stockholm 6-8 December 1985
}

\title{
THE ROLE OF THE VOLAGS
}

\section{Nancy Hatch Dupree}

Research Associate, Center for Afghanistan

Studies, University of Nebraska-Omaha 


\title{
THE ROLE OF THE VOLAGS
}

\author{
Nancy Hatch Dupree
}

It has been six years. In those six years the numbers of Voluntary Agencies (VOLAGs) assisting the Afghan refugees in Pakistan have increased appreciably. There are now upwards of 35 VOLAGs in Pakistan, but just as no one can say exactly how many Afghan refugees reside in Pakistan, so it is impossible to say definitely how many VOLAGs there are.

Yearly we receive "definitive" lists from several sources, official and non-official. No two have ever been the same. What is important, however, is the fact that these VOLAGs represent a commitment on the part of Europe, Africa, the USA, the Arab World, Japan, Pakistan, and Afghans in exile (both in and independent of the political parties).

Our studies began in 1978 as the mass exodus to Pakistan commenced. We were part of that exodus, arriving in August. We watched as the numbers swelled, as tented encampments evolved into mud-brick villages, still officially called Refugee Tented Villages (RTVs) to emphasize the assumed temporary status of the refugees. We agonized with those who first came to establish VOLAG offices in Peshawar and Quetta. How to cope with the enormous influx? How best to ease the physical and psychological trauma of a nation in exile? How 
best to lighten the burden on Pakistan and the Pakistani villagers near whom the refugees settled?

These questions are still uppermost in the minds of assistance programmers, but in the summer of 1985 we noted a high point had been reached. With the realization that the refugee stay will in all probability be a protracted one, goals have broadened beyond emergency relief to include multi-tiered programmes which look toward the future - to the preservation of a culture which may hopefully blossom once again when the refugees return to their homeland.

It is the evolution of this expanded role of the VOLAGs which this paper seeks to address. To define this role now is of consequence because the wel1-bring of the refugees may weIl come to depend more and more heavily on VOLAG assistance. At the $36 \mathrm{th}$ meeting of the Executive Committee (October 1985), the United Nations High Commissioner for Refugees announced that UNHCR faced a shortfall of US\$ 57 million for 1985 , and that there were scant hopes for improvement in 1986. Yet emergency programmes must be continued, because refugees continue to arrive. This is the first priority. Vital care-andmaintenance must be continued, for to overlook their needs would be an "outrage against civilization," as the representative from the Holy see succinctly phrased it. Therefore, the sad conclusion emerges that when funds are limited it is the substantive programmes which are inevitably curtailed by UNHCR. The vital significance of creative VOLAG programming 
N. Dupree - 3

thus becomes acutely apparent; their expertise for stimulating funding crucial.

Goals. The three classic solutions to refugee problems are not fully open to the current Afghan situation in Pakistan: 1) voluntary repatriation, the most desired goal, is for the moment highly elusive, enmeshed in world politics; 2) local integration is not feasible because it would threaten Pakistan's stability, 3) resettlement in a third country can not be entertained because of the size, composition and desires of the majority of the refugee population. The one exception being the approximately 4,350 Turkic-speaking refugees resettled by the Government of Turkey in 1982.

Therefore, while recognizing that repatriation remaing the only viable ultimate goal, the special requirements of temporary asylum have to be considered. While affording a secure and decent livlihood, programes must also prepare the refugees for repatriation. At the same time, the local population should not perceive it is being threatened by the refugee presence nor penalized by special treatment given to the refugees. The needs of the local population can not be divorced from the planning processes. Indeed, often the needs of both groups are one and the same.

For instance, several extensive water systems have been put in place in both the North-West Frontier Province (NWFP) and Baluchistan Province which benefit both local and refugee populations. Labour intensive programmes providing employment 
for both Afghans and Pakistanis upgrade/extend roads, irrigation systems, and implement range management/reforestation schemes. Such programmes initiated by the Government of Pakistan (GOP)/UNHCR are worthy examples of successful attempts to design solutions which emphasize refugee contributions to Pakistan's development.

Most probably these projects would not have been implemented so promptly without the presence of the refugees. In addition, the sooner the refugees are seen to be making economic contributions, the sooner they retrieve their own selfrespect, the sooner they gain acceptance. This diffuses negative Pakistani attitudes before they can errupt into violence.

The aim pending repatriation, therefore, is to introduce programmes of a development nature. This poses both opportunities and challenges.

Access. Although the population is large, access is relatively easier than it was in pre-exodus Afghanistan where there were many small villages scattered in remote, isolated areas. Among the refugees there are a few almost inaccessible groups at the extreme southwestern and northern tips of the 2400 kilometer "refugee arc" along the Afghan-Pakistan border. Also, the mobility of some groups who move seasonally to summer grazing areas, or across the border to farm in the "free" areas of Afghanistan, present problems for implementation. In addition, an uncounted (variously estimated from 130-200,006 refugees live in cities and are generally beyond contact. 
Nevertheless, the bulk of the refugee population is served regularly via a well-established refugee administrative infrastructure which can be easily utilized beyond emergency relief. Never before have so many Afghans been so within reach of development programmers.

\section{VOLAG PARTICIPATION}

THE BEGINNINGS

Before the Government of Pakistan requested UNHCR assistance (May 1979), the Pakistani-based relief organizations met many emergency needs from tents to blankets to basic office equipment for the fledgling refugee administration. It was a chaotic situation. Afghan aid committees sprung up throughout the world and their representatives came to pakistan where local Pakistani manufacturers of canvas tents and other necessitites scrambled unabashedly after the cascades of foreign currency. Hotel gardens in Peshawar and Quetta sprouted with sample tents which were subjected to simulated assaults of wind, dust and rain as harassed VOLAG representatives attempted to determine which would best resist the extremes of nature's wear and tear.

visiting dignitaries came laden with blankets. So much so that many refugees were literally smothered with them. Since the aid distribution system was not yet fully in place, many refugees sold their surplus blankets in order to purchase necessities. This created much ill-will and attracted acrid 
criticism. The seeds of resentment were firmly planted in the minds of some Pakistanis who accused the refugees of being ungrateful opportunists making profit out of the world's generosity. This attitude persists. I

The overburdened administration had also to contend with deliveries of inappropriate foods and outdated drugs accompanied by instructions in languages incomprehensible to those who sought to dispense them. The RTVs were dubbed the dumping grounds of irksome national surpluses. This attitude also persists, albeit to a lesser degree.

Several VOLAGs continue to supply emergency relief which is still desperately needed by certain vulnerable groups, especially new arrivals. Most programmes have moved, however, toward more specialized long-term activities, particularly in the fields of health, education and income-generation.

In broadening their activities, the VOLAGs are assisted by intergovernmental and non-governmental organizations (NGOs) which channel substantial funds through volAGs with established offices in Pakistan. Specialized agencies within the United Nations system also assist UNHCR in its support of VOLAG projects. Finally, the VoLAGs receive positive backing from the GOP through their refugee commissioners in the NWFP, Baluchistan and Punjab provinces.

\section{HEALTH}

Health has been a high priority since the inception of 
the refugee assistance programme because there has always been a genuine fear that epidemics could result from the potentially lethal combination of severe overcrowding, lack of sanitation and poor water supplies.

Also, during the initial stages many aid committees found that donors were particularly attracted by appeals for contributions toward the purchase of vehicles, such as ambulances and mobile health units. A plethora of vehicles arrived, but many soon stood idle because of the high price of petrol. This encouraged the establishment of static Basic Health Units (BHU) within each of the 350 or so RTVs. Donors were also highly receptive to fund-raising campaigns eliciting medicines; medical supply houses responded amenably to requests for large quantities of medicinal drugs. It was not long before some in the VOLAG health system recognized the danger signs inherent in excessive pill-pushing.

Tendencies toward dependency appeared to be developing rapidly as too much time was spent dispensing pills, leaving too few opportunities to concentrate on such important activities as diagnoses, screenings for malaria and TB, evaluations of the nutritional status and basic health care education.

To withdraw that which has come to be expected is to invite vigorous objection. The VOLAG personnel who first discontinued dispensing placebo drugs were regularly subjected to vociferous verbal abuse, mainly from women. The passion 
with which insults were unleashed only served to emphasize the degree to which drug dependency infected the refugee population. Despite these negative signals, however, it was difficult to convince many in the administration that a change of direction was needed. They held that pills should be distributed generously for psychological reasons - "to keep the refugees happy." In addition, many of the doctors resisted moving into health education, considering it beneath their professional status. Persistent VOLAG prodding was needed before these attitudes began to change. The present emphasis on primary health care and education is a major accomplishment for which the VOLAGs merit grateful acknowledgment.

Primary Health Care. Successes in providing more meaningful health assistance have been accomplished through the establishment of Mother-Child Health (MCH) clinics, special care and feeding programmes with emphasis on nutrition education, instruction in oral rehydration therapy for diarrhoea, and health work and dai (midwife or traditional birth attendants) training programmes for basic health services. The programmes are becoming increasingly popular and the women enrolled in them are credited with augmenting attendance at the $\mathrm{MCH}$ clinics. Most importantly, they are spreading the word that better health practices can be as beneficial as pills and injections. Such changes in attitude will have long-lasting effects for generations to come. 
Also, the recognition that effective aid, no matter in what sector, must include women as well as men is gradually being accepted, but much remains to be done in this area.

Other VOLAGs have developed effective training programmes for community health workers. After training (2-3 months) in preventive and basic curative remedies, these workers teach basic health in the RTVs and generally cooperate in social programmes related to health. It is their important function to identify cases of malnutrition, unvaccinated children and those who fail to appear for follow-up shots, difficult birth cases and suspected TB cases to the medical teams at the BHUs.

Training sanitarians responsible for all aspects of sanitation programmes, including community education on the subject, forms an important component of several health programmes.

The importance of these types of training cannot be overemphasized. Rural health services in pre-exodus Afghanistan was hever very efficient, and even the tenuous services which were available are now totally disrupted. Recognizing the emergency of this internal situation, several voldags and international medical teams are devoting their energies to providing doctors, medical supplies and food inside Afghanistan. They also train paramedics and medical support personnel.

At the time of repatriation, therefore, these bodies of 
trained personnel should be able to work together to provide better health for both rural and urban communities. Many ilinesses may be ameliorated by changes in poor eating habits, traditional weaning practices, traditional treatments for diarrhoea which withhold liquids, improper water handling and inadequate personal hygiene. These are precisely the areas included in VOLAG training programmes for health workers. The medical VOLAGs also offer increasing numbers of specialized services. These include: TB control, including contact tracing; obstetrics and gynaecology, pediatrics; physiotherapy, psychiatric referral services; dermatology, eye and dental clinics. Disability screening and referral has been undertaken in some RTVs. Hospitals for the war wounded and paraplegics, with prothesis workshops, have also been established. The paraplegic unit is designed to benefit Pakistanis as well, and provides otherwise non-existent training for Pakistanis in this field. Several VolAGs implement vaccination programmes because the GOP's WHO-assisted Lxpanded Programme for Immunization has been overly strained by the refugee population. The Malaria Control Programme has been similarly overextended, leading some VolAGs to consider training Afghan malaria supervisors in conjunction with the sanitation programmes.

The present refugee health programmes assure the wellbeing of the refugees. There have been no epidemics. Looking beyond the immediate needs, however, the health planning 
seeks to aid Pakistan and prepare the refugees for a healthier post-repatriation life in Afghanistan.

Still to be adequately addressed, however, is the design and production of appropriate visual aids on health subjects. A few sample cloth posters emphasize the efficacy of such materials and highlight possibilities for a new dimension to health assistance. The designing and mass-production of health education materials could perhaps be initiated as an income-generation project. Certainly the results would also be useful for Pakistan where there is a great paucity of all such teaching materials.

\section{EDUCATION}

By and large, the state of education for the Afghan refugees floats in a vacuum in which "the need" is perceived by many, but the "what and how to do" are, at best nebulously defined. The subject of "the correct path" is hotly debated. During the past year or so, however, the importance of VOLAG contributions to this sector have become increasingly apparent. They took the lead in supporting secondary schools not included in GOP/UNHCR primary education assistance programmes in the RTVs. As was the case with health programmes, they also took the lead in establishing schools inside Afghanistan. Initially the assistance was haphazard and generally lacking in quality, however. The move toward a more central role for the VOLAGs in education includes the upgrading of existing schools, the establishment of new schools, the 
creation of curricula and syllabi, the writing and printing of textbooks, the construction of instructional models from available materials, and teacher training. Special courses for the handicapped are in the planning stages. Paraplegics, many of whom are young children and teenagers, have lively minds which deserve to be trained for all manner of professional employment. Courses in Basic English and English for Specific Purposes are also recognized as being esstential for upper level education and employment opportunities in Pakistan.

The production of textbooks is among the more important contributions of the VOLAGs. At present teaching materials are practically non-existent, and often teachers have to dictate the day's lesson before instruction can begin. This component, however, is fraught with frustrations and vexatious challenges because of sensitive ideological differences between the various political groupings in the refugee population. It is hard to reach a consensus, but the impartial professionalism of VOLE:; mediators encourages progress. The role of the go-between is an important function of the VOLAGs which is not be underestimated in all spheres of assistance, but most crucially in the field of education. The need for textbooks is urgent and expediting production will benefit both the refugees in Pakistan and those remaining inside Afghanistan, now and following repatriation. They represent a major tool for preserving the cultural heritage of Afghanistan. 
N. Dupree -13

Others seek to produce reading materials to counter Kabul's dissinformation efforts, including reinterpretations of Afghanistan's history and culture. These cultural organizations operating out of Pakistan are composed predominately of Afghan educationalists and professionals. They write for various audiences, from new literates to fellow scholars and professionals, inside Afghanistan and throughout the world.

VOLAGs also act as catalysts in the registration and evaluation of Afghan education professionals. The conferences they hold serve as links between those in need and those with resources to offer, in Pakistan and inside Afghanistan. For the first time since the exodus a measure of coordinated effort seems to be emerging because of the efforts of the VOLAGs. Added dimensions continually come to light, presenting new challenges. Undoubtedly programmes in this sector will branch out in exciting new directions which will have important repercussions on post-repatriation Afghanistan. of particular import are the moves toward providing enhanced education for urban youth, both men and women. Most urban refugees do not qualify for GOP/UNHCR assistance because they do not live in the RTVs. Generally from the middle class, they represent Afghanistan's future educators and implementors. Yet too many are idle and until recently they have been dangerously neglected.

This is doubly distressing for young teenage girls and young women living in the urban areas whose future is cruelly bleak. In pre-coup Afghanistan urban girls had taken an 
education for granted and looked forward to a variety of career opportunities. These young women now face the ire of ultra-conservative religious leaders who seek to curtall their activities outside the home. Courageous tentative beginnings to provide new opportunities for these women have been taken by certain VOLAGs, but the entire dimension of the problems and potential of education for young urban women among the refugee population is almost totally unexplored and in urgent need of study.

Adult Education. Surprisingly, not much has been explored regarding the question of adult education. One VOLAG produces effective literacy teaching materials in Pashto which is a significant contribution because the refugees are predominately Pashto-speakers and Pakistan has no comparable materials for 1ts Pashto-speaking population. Teacher-training related to the teaching materials and non-formal education is included in this programme which is area-oriented and seeks the participation of an equal number of Pakistanis living in neighboring villages. Continuing investigations puruse innovative non-formal subjects for implementation.

Education Aids. Also still to be considered are the production of educational visual aids, radio cassettes, and the possibilities of radio programing, powerful education weapons. Any public education radio programs developed now would continue to be of service when the refugees return to. their villages in Afghanfstan. In addition to instructing in 
diverse fields from health to the various sciences, the positive aspects of entertainment should not be overlooked. Folktales, for instance, reinforce cultural values. Visual aids can also impart more than simple information. A large major1ty of young children in the RTVs left Afghanistan as babies and infants too young to vizualize their homeland. Many thousands born in the RTVs are now six years old. There are no textbooks which describe the geography of Afghanistan, no posters depict the beauty of 1ts landscape. Education materials such as film strips would enhance both non-formal and formal education programs, in the RTVs in Pakistan and in the free zones inside Afghanistan, and strengthen ties to their heritage and homeland,

To further this objective a central visual aid depository/library would seem to be a worthy project for future consideration. Films on teaching methods have also proved useful. Such an institution could be combined with a reading library of multi-lingual books about Afghanistan. Composed of materials at all reading levels, it should be centrally located and open to all.

\section{INCOME-GENERATION}

Exile has forced many Afghan refugees to modify ideals concerning role and status. Most are from the rural areas, To till the land and be self-rellant in providing well-being for a family is a matter of pride, a symbol of ldentity, self- 
respect and esteem to most rural Afghans. The Pushtun, particularly, generally look on trade and service as less desirable occupations.

For those who have not been able to make this transition, idleness and a sense of 108 s of purpose combine to create a pre-disposition toward dependency which threatens to demoralize a people long lauded for their self-reliance. Dependency attitudes are insiduous, and, because they can so easily become an attitudinal habit, they jeopardize the very essence of Afghan culture.

In all faimess, it must be noted that such attitudes are most noticeable in the "fashionable" RTVs frequently visited by foreigners dispensing "freebees" in the spirit of Lady Bountiful - whether for political merit, or simply to assuage consciences. Thousands of rupee notes and other commodities are distributed indiscriminately, and only fools would fail to take advantage of such handouts and seek more from the next visitor. Outsiders must, therefore, share in the blame for these manifestations of dependency.

Even a cursory glance reveals a tremendous dynamism in most of the RTVB, however. The Afghans have initiated numerous self-reliance endeavors. Nevertheless, although the refugees participate in a wide range of economic activities, there is a high rate of underemployment due in part to limited markets, lack of appropriate tools, and poor quality merchandise related to the unavallability of quality raw materials. Many Afghan therefore seek opportunities in the Pakistani 
economy. The massive disbursement of refugees seeking employment outside the RTVs has caused some to worry that the concept of an Afghan nation in exile is being erroded, adverse$1 y$ affecting Pakistan politics. To counter this, efforts are being made to develop services which will make the RTVs more attractive and self-sustaining.

Income-generating projects. VOLAG-implemented incomegenerating projects concentrate on vocational training, supplementary training, and skills development for productionoriented projects. Some emphasize the production of refugeerelated products such as quilts and clothing, particularly hospital gowns and school uniforms. Others seek to develop skills which, while generating extra income now, will estabIish a basis for Afghanistan's future development when the hoped-for return of the refugees takes place. These include auto-mechanics, domestic and commercial electricity, welding, plumbing, carpentry, masonry, construction, talloring, shoemaking, weaving carpets, blankets and cotton fabrics, women's and children's fashion designing and production, beekeeping. All the VOLAGs are on the alert for new possibilities. Major efforts are being made to identify and assist skilled Afghans, an estimated $10 \%$ of the refugee population. Building on the philosophy that the best solution to many problems is to help the refugees help themselves, some VOLAGs provide tools and capital so that more refugees may extend enterprises or establish new businesses of their own. 
Special attention is given to the identification of employment activities for refugee women for several pilot projects have demonstrated that refugee women have the capacity and motivation to participate in income-generation projects. For the moment these emphasize health-related programmes plus embroidery, tailoring and quilt-making, and to some extent poultry and kitchen gardening which are considered to be income-enhancing. The ldentification, selection of natural leaders and the promotion of responsible leadership development is vital to these endeavors.

Increased production, by both the skilled and the newlytrained, introduces the problems of marketing, a longneglected component now being addressed in preparation for the opening of a sales depot for Afghan produced goods.

\section{RELIEF SUBSTITUTION}

The expected long-term stay and soaring financial burden have led to recommendations that rellef aid to all but the most vilnerable groups be gradually decreased. In advocating the substitution of income for relief, it is also recommended that during the phasing out period, all relief substitution activities initiated by the refugees be fully facilitated, particularly when they compliment Pakistan's development sector. Past experience has shown that the most successful projects have been those which included refugees in their design, management and implementation. 
N. Dupree -19

Projects on a grander scale are also envisioned. These include training hospitals, truck farms, dairy 11vestock breeding and industrial estates with their own training components. These would provide employment and products for both the refugees and Pakistanis, but most significantly the policy of substituting income for relief projects stresses training as an all important compliment to income-generation. For instance, the majority of the refugees are farmers/herders, yet they are presently prohibited from substantive private farming because this would compromise their temporary status as refugees. As refugees they are also discouraged from keeping large herds because these ravage Pakistan's ecology. How then are the children of these peasant farmers/herders to survive on returning to Afghanistan if they are denied learning experiences in Pakistan? How will even minimal industry develop? These types of larger projects seek to provide a solution.

To assess the feasibility of these large projects, UNHCR has engaged NESPAK (National Engineering Services/Pakistan), a Karachi-based private firm with over 1000 professionals to evaluate the impact of projects on both the refugees and Afghanpakistan relations. The institution of standardized demographic data-collection would greatly facllitate their efforts, as well as the implementation of VOLAG programmes. In addition, VOLAG input into data-collection systems could be far reaching. There are some who worry about the small numbers of 
benficiaries involved in current VOLAG projects. Certainly the quality of individual programmes is uneven. Lack of coordination sometimes results in duplication. In fact, there are critics who regard any attempts to achieve selfsufficiency as unrealistic. Even if $60-80 \%$ self-rellance could be achleved, would it be politically feasibly to institute relief substitution? Many think not. Many believe the effort must be made.

Whichever the point of view, the diverse roles pursued by the VOLAGs are exerting a significant impact on Afghanistan's present, in Pakistan and inside Afghanistan. A laudable groundwork has been laid which provides wide scope for future joint action in the battle to conserve this culture so that once again it may flourish. Afghanistan may never be the same. That cannot be denied. But all concerned should endeavor to help retain the essence of Afghan culture. Bodies such as the distinguished Swedish Institute of International Affairs can fulfill a two-pronged mission by influencing main-stream aid agencies to address problems by identifying creative goals, and acting as catalysts for funding so that the goals may be realized.

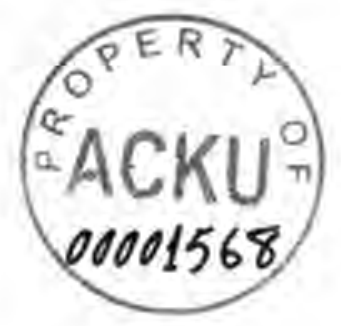




$\left[\begin{array}{c}A R A B \\ R \\ 5,73 \\ D \cup P \\ (1568)\end{array}\right]$

